\title{
RETRACTED ARTICLE: Cost-effectiveness of dual energy X-ray absorptiometry (DXA) plus anti-resorptive treatment in Australian women with breast cancer who receive aromatase inhibitors
}

Przemyslaw Marcin Sowa • Martin J. Downes •

Louisa G. Gordon

Received: 6 November 2014 / Accepted: 20 February 2015 / Published online: 3 April 2015

(C) The Japanese Society for Bone and Mineral Research and Springer Japan 2015

After publication of the article, the authors have reassessed the behavior of the mathematical model and discovered that in some model cycles, the transition probabilities were not appropriately picked from the input tables. Therefore, the authors have retracted the article. The authors sincerely regret this error and any confusion it may have caused.

P. M. Sowa $(\bowtie) \cdot$ M. J. Downes · L. G. Gordon Centre for Applied Health Economics, Menzies Health Institute Queensland, Griffith University, Meadowbrook, QLD 4131, Australia

e-mail: m.sowa@griffith.edu.au 